\title{
Twenty-first-century climate impacts from a declining Arctic sea ice cover
}

Article

Published Version

Singarayer, J. S., Bamber, J. L. and Valdes, P. J. (2006)

Twenty-first-century climate impacts from a declining Arctic sea ice cover. Journal of Climate, 19 (7). pp. 1109-1125. ISSN 1520-0442 doi: https://doi.org/10.1175/JCLI3649.1 Available at https://centaur.reading.ac.uk/34496/

It is advisable to refer to the publisher's version if you intend to cite from the work. See Guidance on citing.

Published version at: http://dx.doi.org/10.1175/JCLI3649.1

To link to this article DOI: http://dx.doi.org/10.1175/JCLI3649.1

Publisher: American Meteorological Society

All outputs in CentAUR are protected by Intellectual Property Rights law, including copyright law. Copyright and IPR is retained by the creators or other copyright holders. Terms and conditions for use of this material are defined in the End User Agreement.

\section{www.reading.ac.uk/centaur}

\section{CentAUR}

Central Archive at the University of Reading

Reading's research outputs online 


\title{
Twenty-First-Century Climate Impacts from a Declining Arctic Sea Ice Cover
}

\author{
Joy S. Singarayer, Jonathan L. Bamber, and Paul J. Valdes \\ School of Geographical Sciences, Bristol University, Bristol, United Kingdom
}

(Manuscript received 14 October 2004, in final form 20 April 2005)

\begin{abstract}
A steady decline in Arctic sea ice has been observed over recent decades. General circulation models predict further decreases under increasing greenhouse gas scenarios. Sea ice plays an important role in the climate system in that it influences ocean-to-atmosphere fluxes, surface albedo, and ocean buoyancy. The aim of this study is to isolate the climate impacts of a declining Arctic sea ice cover during the current century. The Hadley Centre Atmospheric Model (HadAM3) is forced with observed sea ice from 1980 to 2000 (obtained from satellite passive microwave radiometer data derived with the Bootstrap algorithm) and predicted sea ice reductions until 2100 under one moderate scenario and one severe scenario of ice decline, with a climatological SST field and increasing SSTs. Significant warming of the Arctic occurs during the twenty-first century (mean increase of between $1.6^{\circ}$ and $3.9^{\circ} \mathrm{C}$ ), with positive anomalies of up to $22^{\circ} \mathrm{C}$ locally. The majority of this is over ocean and limited to high latitudes, in contrast to recent observations of Northern Hemisphere warming. When a climatological SST field is used, statistically significant impacts on climate are only seen in winter, despite prescribing sea ice reductions in all months. When correspondingly increasing SSTs are incorporated, changes in climate are seen in both winter and summer, although the impacts in summer are much smaller. Alterations in atmospheric circulation and precipitation patterns are more widespread than temperature, extending down to midlatitude storm tracks. Results suggest that areas of Arctic land ice may even undergo net accumulation due to increased precipitation that results from loss of sea ice. Intensification of storm tracks implies that parts of Europe may experience higher precipitation rates.
\end{abstract}

\section{Introduction}

Studies from a variety of sources have documented evidence for recent change in the environment of high northern latitudes (Serreze et al. 2000; Johannessen et al. 2004). Observations of Arctic sea ice from satellite passive microwave radiometer data have demonstrated a downward trend in both annual mean ice extent (area within the ice-ocean margin) and ice area (extent minus open water area within the ice pack) of $-2 \%$ and $-3 \%$, respectively, during the last $25 \mathrm{yr}$ (Parkinson et al. 1999; Johannessen et al. 2004; Comiso 2002a). Sea ice thickness has also decreased in recent decades (Rothrock 1999; Laxon et al. 2003; Johannessen et al. 2004), although estimates vary considerably and the variability is less well known than that of ice extent.

Corresponding author address: Dr. Joy S. Singarayer, School of Geographical Sciences, Bristol University, Bristol Road, Bristol BS8 1SS, United Kingdom.

E-mail: joy.singarayer@bris.ac.uk
Over the same time period global temperatures have increased, with largest increases over land between $40^{\circ}$ and $70^{\circ}$ latitude in winter/spring. Global circulation models (GCMs) predict that anthropogenic greenhouse gas warming will be amplified at northern high latitudes (Räisänen 2001), due in part to ice-albedo feedback mechanisms arising from continuing decline in Arctic sea ice.

Dowdeswell et al. (1997) examined 40 Arctic ice caps and glaciers and found that most have had negative mass balances over the past few decades, while a few, in parts of Scandinavia and Iceland, have been positive because of increased winter precipitation. Bamber et al. (2004) attribute an anomalous positive elevation change between 1996 and 2002 on the largest ice cap in the Eurasian Arctic (Austfonna, eastern Svalbard) to an increase in accumulation rate due to loss of local perennial sea ice and resultant local increase in precipitation. Kattsov and Walsh (2000) also tentatively associated observational and modeled trends in precipitation with changes in the sea ice boundary. The possi- 
bility of further decreases in sea ice over the next century, given current trends, suggests that there may be significant impacts for the mass balance of other Arctic land ice.

Projections of continuing decline in the Arctic sea ice cover for the coming decades are supported by GCM simulations under global warming scenarios (Vinnikov et al. 1999; Walsh and Timlin 2003; Gregory et al. 2002). The predicted trends vary considerably across various models (Walsh and Timlin 2003). However, simulated decreases are consistently larger in summer, with much of the Arctic Ocean being ice free during the summer minimum by the end of the twenty-first century. As such, sea ice is often used as an indicator of climate change. However, it also plays an active role in the climate system through its influence on ocean-toatmosphere fluxes, surface albedo, and ocean buoyancy.

It is difficult from data analysis alone to establish what impact sea ice anomalies have on climate. It can also be relatively difficult using fully coupled GCMs to elucidate information concerning the active influence of sea ice from total greenhouse-gas-induced climate change. Modeling and observational studies have found that atmospheric influence on sea ice by thermodynamic and wind stress forcing generally dominates (e.g., Maslanik et al. 2000; Deser et al. 2000; Partington et al. 2003), hampering detection of sea ice forcing on the atmosphere. An exception to this is the sea ice cover east of Greenland, which has been shown, using observational datasets, to affect the position of the local storm track through surface heat flux anomalies (Deser et al. 2000); it has also been shown that reductions in sea ice have been associated with decreased sea level pressure in this area (Slonosky et al. 1997). Rind et al. (1995) have estimated that sea ice composes $37 \%$ of the temperature sensitivity to $\mathrm{CO}_{2}$, in $2 \times \mathrm{CO}_{2}$ experiments where sea ice changes were artificially prevented, which importantly diminished cloud cover and water vapor feedbacks.

Several recent AGCM simulations have examined atmospheric circulation changes associated with surface boundary conditions (sea ice and sea surface temperature). For example, Parkinson et al. (2001) ran an AGCM with uniformly larger and smaller ice concentrations to quantify how inaccuracies in sea ice data might affect atmospheric simulations. They found that surface air temperatures (SATs) increased linearly as ice concentration decreased, with the greatest changes in winter in regions directly above changes in ice. Alexander et al. (2004) used actual ice extents for recent winters with particularly large positive or negative anomalies to force the National Center for Atmospheric Research (NCAR) Community Climate Model (CCM3). They found local warming, enhanced precipitation, and reduced sea level pressure directly over areas of sea ice reductions and the reverse for regions of increased sea ice, also found by Singarayer et al. (2005). Ice anomalies in the Atlantic sector produced a largescale response resembling the Arctic Oscillation/North Atlantic Oscillation (AO/NAO). Studies by Magnusdottir et al. (2004) and Deser et al. (2004) examined the atmospheric response to both sea ice extent and sea surface temperature (SST) anomalies confined to the North Atlantic region, with both studies also using CCM3. Trends in the boundary conditions were derived from the last $40 \mathrm{yr}$, although the anomalies were amplified, and the anomalies were calculated to correspond to the pattern of the trend, varying seasonally but not changing from year to year. Sea ice anomalies were more efficient at producing an atmospheric response than SST anomalies. The response to sea ice anomalies was opposite to the observed atmospheric trend, suggesting a negative ice-atmosphere feedback.

In this study we investigate the direct climate impacts of decreasing Arctic sea ice using an atmospheric GCM. We perform atmospheric simulations on the Hadley Centre Atmospheric Model (HadAM3) while varying prescribed Arctic sea ice alone to represent the continuing decline predicted for the twenty-first century. In contrast to the studies described above, we vary Arctic sea ice concentrations from year to year using trends for this century derived from observed data. The local and large-scale atmospheric response to sea ice decline is examined. A further simulation investigates the response to combined sea ice decline and correspondingly increasing SSTs, also using HadAM3. By the use of an atmospheric-only model these simulations focus on the influence of sea ice on the albedo and ocean-atmosphere fluxes only. A subsequent study will investigate ocean buoyancy effects.

\section{Methods}

\section{a. Observations of recent changes in Arctic sea ice}

Passive microwave radiometer (PMR) satellite data have provided the most comprehensive record of sea ice concentrations for the entire Arctic since 1978. Various algorithms have been formulated to derive sea ice concentrations from PMR, such as the National Aeronautics and Space Administration (NASA) team (Cavalieri et al. 1991) and bootstrap (Comiso et al. 1997) algorithms. There are discrepancies in the concentrations from different datasets that can be up to $20 \%$ in summer (Partington et al. 2003; Singarayer and 


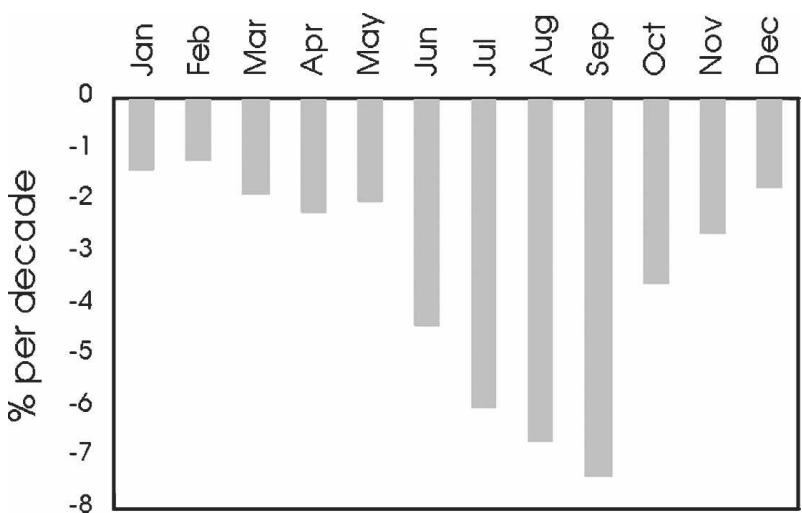

FIG. 1. Average trend in Arctic sea ice covered area for each month (\% per decade). Monthly mean sea ice concentrations (1980-2000) from passive microwave radiometer data derived using the Bootstrap algorithm were used.

Bamber 2003), which are the result of the various methods used to handle ice temperature fluctuations or seasonal variations in ice/water signatures, for example. Previous comparisons have found that the Bootstrap record may be more reliable than others (Comiso et al. 1997; Singarayer and Bamber 2003). Therefore, Bootstrap-derived sea ice concentrations were used in this study; they are publicly available from the National Snow and Ice Data Center (Comiso 2002c; 25 km resolution on a polar stereographic projection).

The decline in annual mean Arctic sea-ice-covered area calculated from the Bootstrap record is 3\% per decade from 1980 to 2000. Examination of monthly mean trends shows that this decrease is strongly weighted to the summer months (Fig. 1), although there has been a reduction in all months over this time period. The perennial sea ice cover, as described by the summer minimum, is reducing at a rate of $9 \%$ per decade (Comiso 2002b). Comiso (2002a) observed a much more variable summer ice cover in the 1990s than the 1980s, suggesting a thinning in perennial ice in the last two decades.

The spatial distribution of change in Arctic sea ice is not uniform. The largest decreases in concentration have occurred around the ice margin (Parkinson et al. 1999; Comiso 2002b), in the Bering, Okhotsk, and Greenland-Iceland-Norway (GIN) Seas in winter, and along the Siberian/north Eurasian coast and Canadian Archipelago in summer. Anomalies in ice concentrations in these regions are strongly correlated with surface ice temperature anomalies (Comiso 2002a). Partington et al. (2003), using empirical orthogonal function analysis, show that the major modes of Northern Hemisphere sea ice variability, distributed chiefly in these marginal regions, exhibit a 1-yr lagged response to the North Atlantic Oscillation. These modes account for $18 \%$ of the total monthly variance.

\section{b. Projected sea ice trends}

Observations over the last few decades show an overall monotonic, approximately linear decline in Arctic sea ice area and extent. Coupled climate model predictions under increasing $\mathrm{CO}_{2}$ scenarios result in continuing decreases for the next century (Walsh and Timlin 2003). The magnitude varies considerably between models. However, several models predict that the Arctic Ocean will be almost ice free in summer by the end of the twenty-first century.

To examine the effects on climate of a continuing decline in Arctic sea ice the trends obtained from the Bootstrap record of sea ice concentration for 1980-2000 were projected up to 2100 . A monthly mean dataset of future sea ice concentrations was achieved by first calculating a trend for each month from a time series at each grid point. The calculated linear trends were extrapolated for a further hundred years. The resulting predicted sea ice area time series for the March and September monthly means are displayed in Figs. 2a and 2b, respectively ("ICE1" lines). Over the period 1980 2100 , March ice-covered area decreases by $\sim 8 \%$, and September area decreases by $\sim 39 \%$. In summer especially, this trend is conservative when compared to HadCM3 coupled model predictions (Walsh and Timlin 2003). The slower decline is because the main ice pack has a slower rate of decline than the ice edge, and when the current ice edge disappears, the ice that is left to form the new ice edge reduces more slowly than it would in reality.

Consequently, a second sea ice time series was constructed that used the same observed Bootstrap trends whilst including an additional time-dependent factor (different for each month) to allow the total mean icecovered area to continue decreasing roughly linearly with the same gradient, as calculated for the observed period (1980-2000). March and September time series are shown in Figs. 2a and 2b ("ICE2"). In this case, the decreases from 1980 to 2100 are $26 \%$ and $82 \%$, respectively. Such large decreases in total ice-covered area and continuing quasi-linear trends are comparable in magnitude to those simulated by some of the more severe Intergovernmental Panel on Climate Change (IPCC) scenarios (Gregory et al. 2002).

There is reasonable consistency between the observed and predicted portions of Fig. 2. No additional noise/variability was introduced to the predicted sea ice fields. Figure 3 depicts the predicted spatial distribution of sea ice in March (Fig. 3a) and September (Fig. 3b) in 


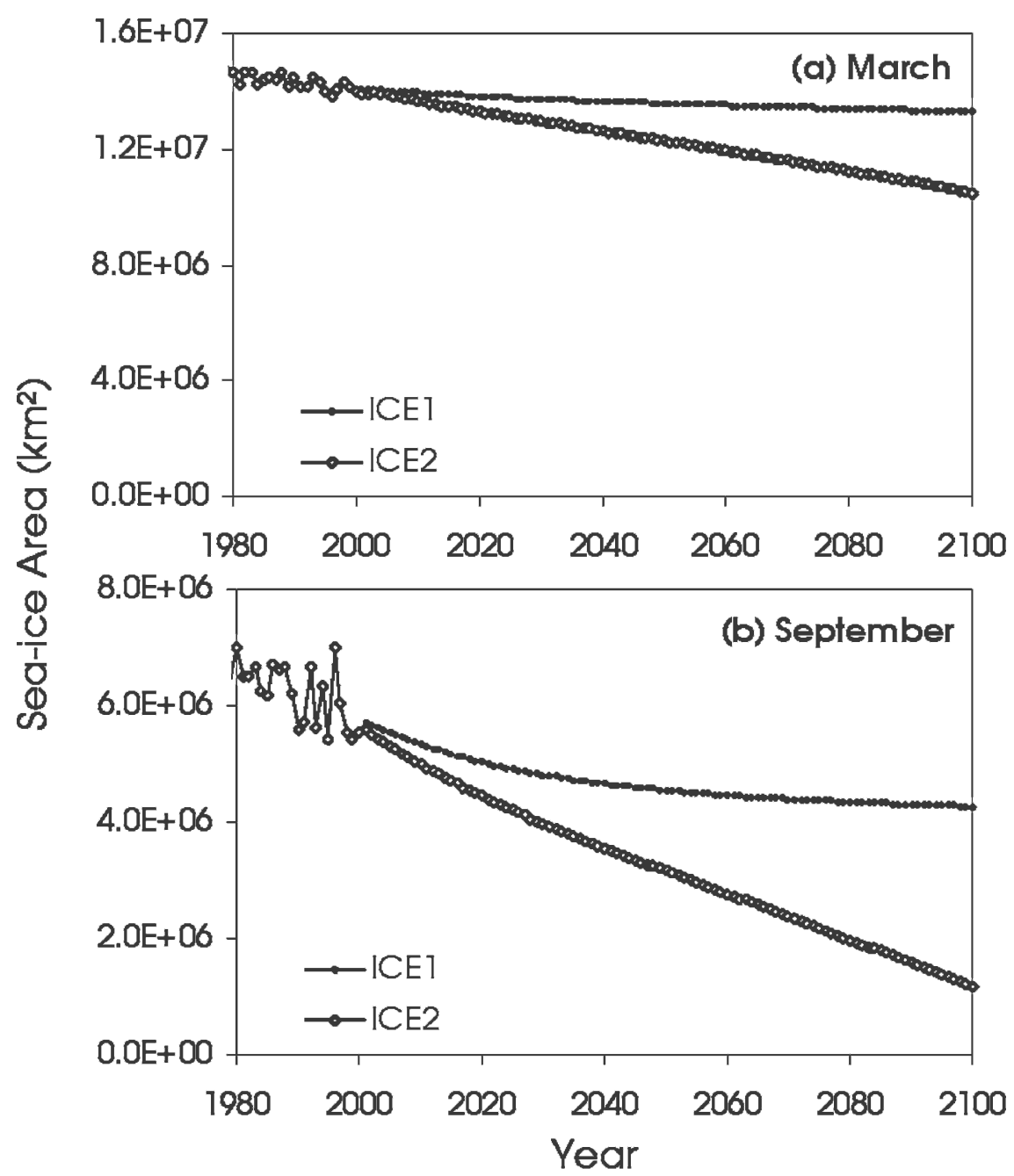

FIG. 2. Time series of (a) March mean and (b) September average Arctic sea ice areas. Observed data are used from 1980 to 2000, and observed linear trends are extrapolated to give predicted ice areas up to 2100 (filled symbols; ICE1). Open symbols (ICE2) provide a dataset with a faster rate of sea ice decline. See text for details.

the years 2000, 2025, 2050, 2075, and 2099 for both the ICE1 and ICE2 data. In March, the ice fractions in the central Arctic show little decrease in ICE1. ICE2 show larger decreases than ICE1 in marginal ice areas such as the Bering, Okhotsk, and Barents Seas, as well as small central Arctic decreases. Summer minimum ice extent (Fig. 3b) is reduced to the high Arctic, and there is also a significant increase in the amount of open water within the ice pack, that is, the ice concentrations are lower, resulting in greater decrease in ice-covered area than ice extent, similar to observed (Comiso 2002a; Parkinson et al. 1999). ICE1 displays some areas with high ice fractions even in 2099, as well as ice in the Fram Strait. September ice fractions in ICE2 are mostly $<0.5$ by 2099 , and the extent is smaller than ICE1, which is more consistent with coupled model predictions (Johannessen et al. 2004).

The ICE1 dataset provides a moderate scenario of sea ice decline, whereas the ICE2 dataset provides a more severe scenario. The techniques used here to estimate future sea ice and the assumption of linear trends may be simplistic. However, the sea ice datasets that have been constructed allow the simulation results to bracket a range of possible estimates of Arctic sea ice decline to the end of this century that can test the sensitivity of climate-to-sea ice reductions.

\section{c. Experimental setup}

Two datasets of $120 \mathrm{yr}$ of monthly mean sea ice fractions were compiled from Bootstrap observations from 
(a) Mar
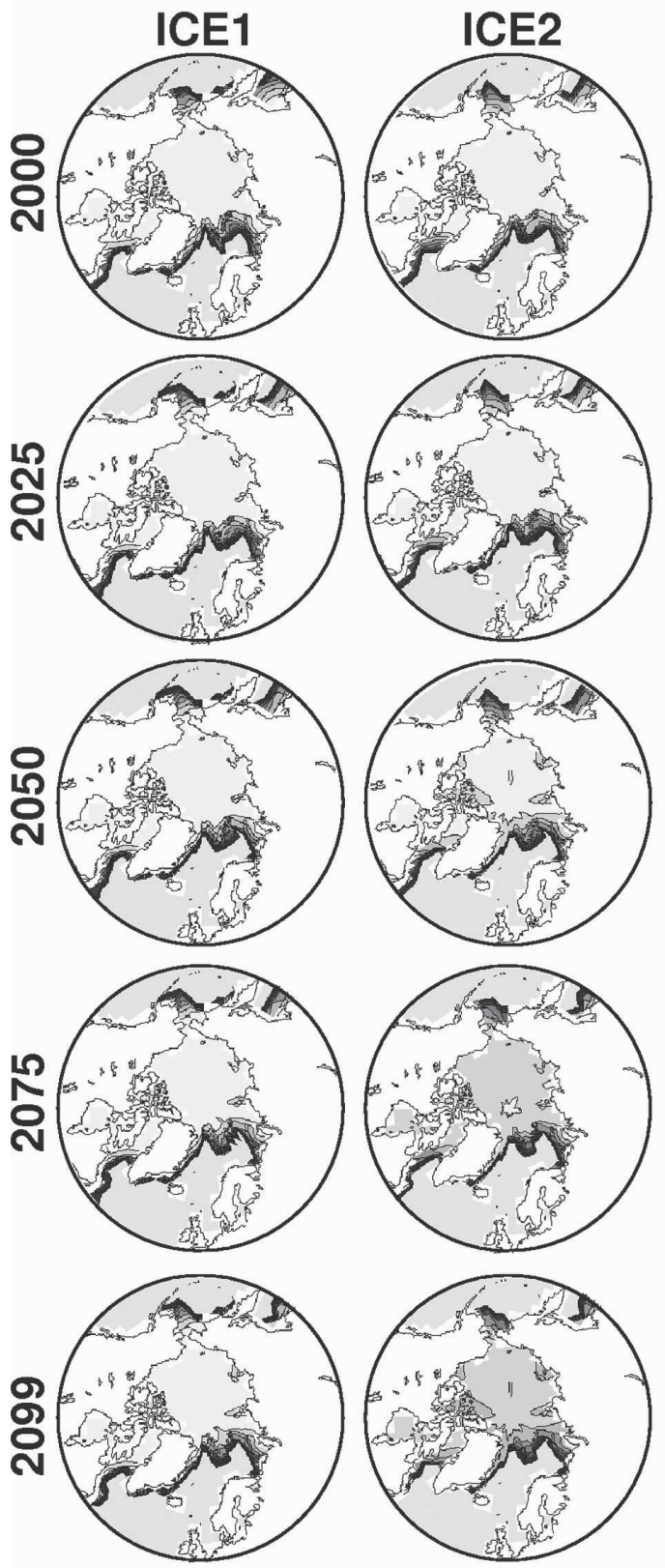

(b) Sept
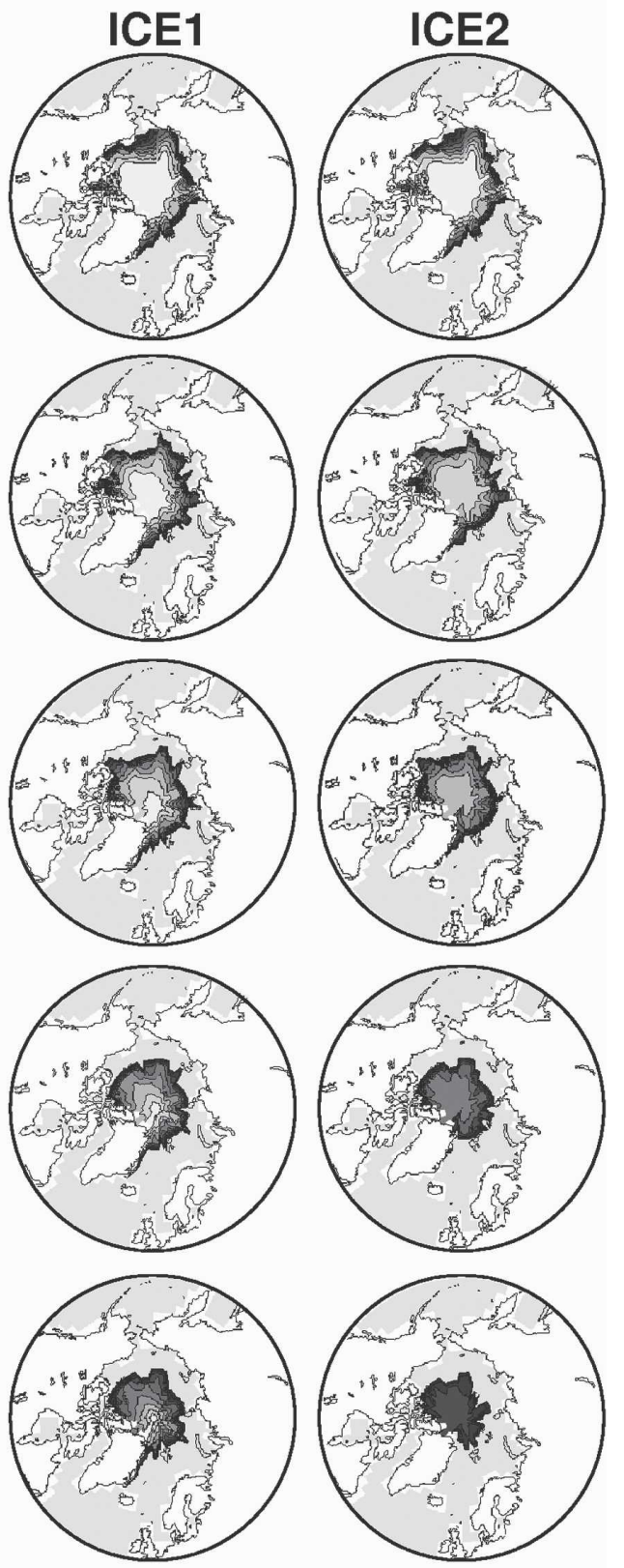

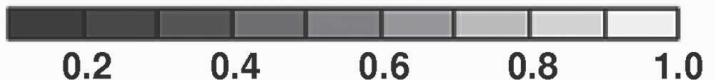

FIG. 3. Spatial maps of sea ice for the two datasets ICE1 and ICE2 for years 2000, 2025, 2050, 2075, and 2099 in (a) March and (b) September.

1980 to 2000 and projected trends for 2001 to 2100 (ICE1 and ICE2). These were used to drive HadAM3. Sea ice depth was calculated within the model as a function of ice fraction. Snow depth over sea ice was modeled. To ensure that any changes in climate are solely a result of changes in Arctic sea ice, a climatological Ant- arctic sea ice cover was used that was derived from the U.K. Met Office (UKMO) sea ice climatology. Ten years of climatological sea ice was prescribed for 197080 to allow for model spinup. Following the spinup period, three experiments were performed, as listed below: 
1) EXPT1: HadAM3 with prescribed sea ice from the ICE1 time series and climatological SST field.

2) EXPT2: HadAM3 with prescribed sea ice from the ICE2 time series and climatological SST field (run as an ensemble consisting of six simulations with initial-condition perturbations).

3) EXPT3: HadAM3 with prescribed sea ice from the ICE2 time series and increasing SST field.

In all experiments, the sea ice prescription for 19802000 is the same.

SSTs were based on the Global Sea Ice and Sea Surface Temperature (GISST) climatology (Parker et al. 1995). The climatological SST field was modified slightly for use in EXPT1 and EXPT2 so that grid points that were ice covered at any time for a particular month were given an SST of $271.35 \mathrm{~K}$ in the climatology (freezing point of saline water). For EXPT3 a representation was introduced of the increase in SSTs as sea ice decreases, as would occur because of increased absorption of radiation by the ocean. The rate of increase was based on previous coupled simulation results with the Third Hadley Centre Coupled Ocean-Atmosphere GCM (HadCM3). A simple function was fitted to describe the change in SST with sea ice concentration, only used for grid boxes that initially had nonzero ice concentrations. Different constants were used for each month, so that any SST increases due to lower sea ice concentrations were larger in the summer months than in winter.

The atmospheric model used, HadAM3, is a component of the coupled HadCM3 model, a version of the UKMO unified forecast and climate model. HadAM3 is run at a horizontal resolution of $2.5^{\circ}$ latitude $\times 3.75^{\circ}$ longitude using 19 vertical hybrid coordinate levels and a time step of $30 \mathrm{~min}$. The atmospheric boundary layer can occupy up to the bottom five model layers (Johns et al. 1997), and the parameterization uses MoninObukhov similarity theory. A first-order turbulent mixing scheme is used to mix the conserved thermodynamic variables and momentum in the vertical (Smith 1990). A land surface scheme, the Met Office Surface Exchange Scheme (MOSES; Cox et al. 1999), which includes a representation of soil moisture freezing and melting and should lead to better simulations of surface temperatures, is included. A zero heat flux condition is imposed at the base of the soil model to conserve heat within the system. Over land, surface roughness characteristics are prescribed according to climatological surface type. At sea points, however, the roughness length over open water is computed from local wind speeds. Where there is partial sea ice cover, separate fluxes are computed for sea ice and leads within a grid box. A full description of the model and revisions made from the previous versions can be found in Pope et al. (2000). Trace gas concentrations were set to preindustrial concentrations and held constant throughout the run, thus emphasizing the role of sea ice only.

Because of the prescription of SSTs, the model does not fully conserve energy since energy absorbed in the ocean is not permitted to warm it. It should be noted also that because of the specification of SSTs, the full effect of sea ice changes on climate cannot be assessed from these simulations because of limits of oceanic feedbacks. However, the three experiments enable the isolation of sea-ice-induced climate changes, which are difficult to disentangle in coupled experiments, particularly because atmosphere-to-sea ice forcing normally dominates.

\section{Results}

\section{a. Atmospheric changes due to observed Arctic sea ice decline (1980-2000)}

The results presented in this section are taken primarily from the EXPT2 ensemble run. SAT is a useful field to examine, as it integrates changes in surface energy budget. There are significant increases in simulated surface air temperature as a result of the decrease in sea ice cover during the $20 \mathrm{yr}$ of observational data. Modeled Arctic annual average SATs $\left(60^{\circ}-90^{\circ} \mathrm{N}\right.$ latitude) show a positive trend of $0.11^{\circ}-0.23^{\circ} \mathrm{C}$ per decade for the six simulations (Fig. 4a), compared with the observed $0.33^{\circ} \mathrm{C}$ per decade (data from Lugina et al. 2003). Comiso (2003) also calculated an observed SAT trend of $0.33^{\circ} \pm 0.16^{\circ} \mathrm{C}$ per decade from 1981 to 2000 over sea ice, using satellite thermal infrared data (and $0.5^{\circ} \mathrm{C}$ per decade over Eurasia, $1.06^{\circ} \mathrm{C}$ per decade over North America). The average simulated SAT increase $\left(0.16^{\circ} \pm 0.6^{\circ} \mathrm{C}\right.$ per decade $)$ is roughly half that observed over the Arctic.

The use of a constant SST field may contribute to producing a smaller trend and smaller interannual variability in the modeled data than observed. The EXPT3 simulation, which included an increasing SST field, produced a larger trend for the period $1980-2000$ of $0.38^{\circ} \mathrm{C}$ per decade, although the simulated interannual variability was still less than observed.

The difference between modeled and observed global annual change in SAT is greater than for the Arctic alone. Between 1980 and 2000 the simulated global annual temperature increases by less than $0.05^{\circ} \mathrm{C}$ compared with an observed increased of $\sim 0.3^{\circ} \mathrm{C}$. Even global annual temperatures in EXPT3 increase by only $0.051^{\circ} \mathrm{C}$ during the same period. This suggests that sea 


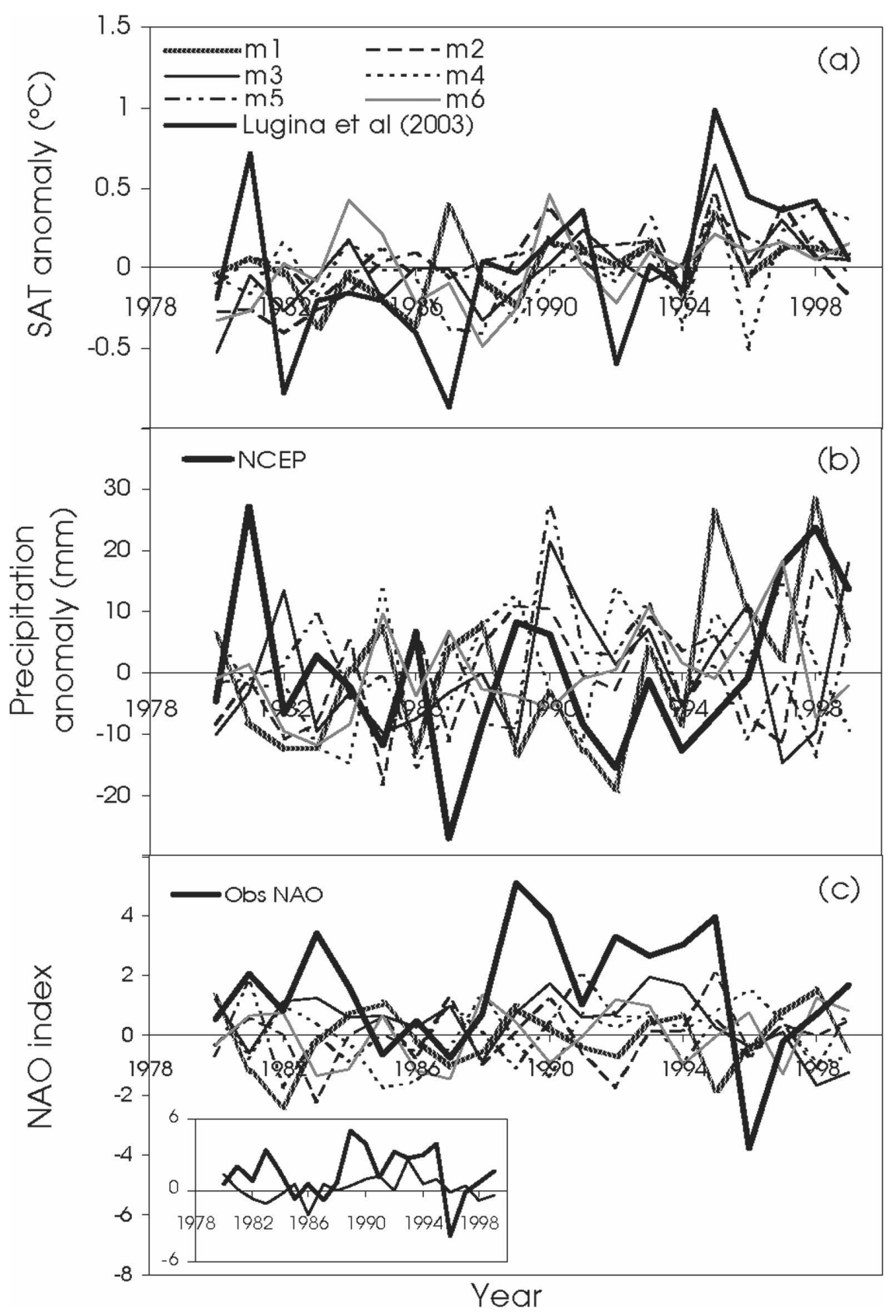

FIG. 4. Time series from 1980 to 1999 of (a) simulated Arctic $\left(60^{\circ}-90^{\circ} \mathrm{N}\right)$ annual mean SAT anomalies from each ensemble member ( $\mathrm{m} 1, \mathrm{~m} 2, \mathrm{~m} 3, \mathrm{~m} 4, \mathrm{~m} 5$, and $\mathrm{m} 6)$, and observed data from Lugina (2003). (b) Simulated Arctic annual mean total precipitation anomalies from each ensemble member, and NCEP reanalysis. (c) Observed normalized NAO index compared with modeled. NAO index data provided by the Climate Analysis Section, NCAR, Boulder, CO; Hurrell (1995). Inset shows the simulated ensemble average NAO index. See text for details.

ice changes are only a small component of global change.

Both the observed and mean ensemble annual Arctic SAT time series from 1980 to 2000 demonstrate significant anticorrelations with annual sea ice area, with cor- relation coefficients of -0.71 and -0.88 , respectively. The simulated and observed data correlate most strongly in years 1993-96, noted as being years with the largest interannual variation in ice area (e.g., 1995 had the lowest annual sea ice area of the observed period 

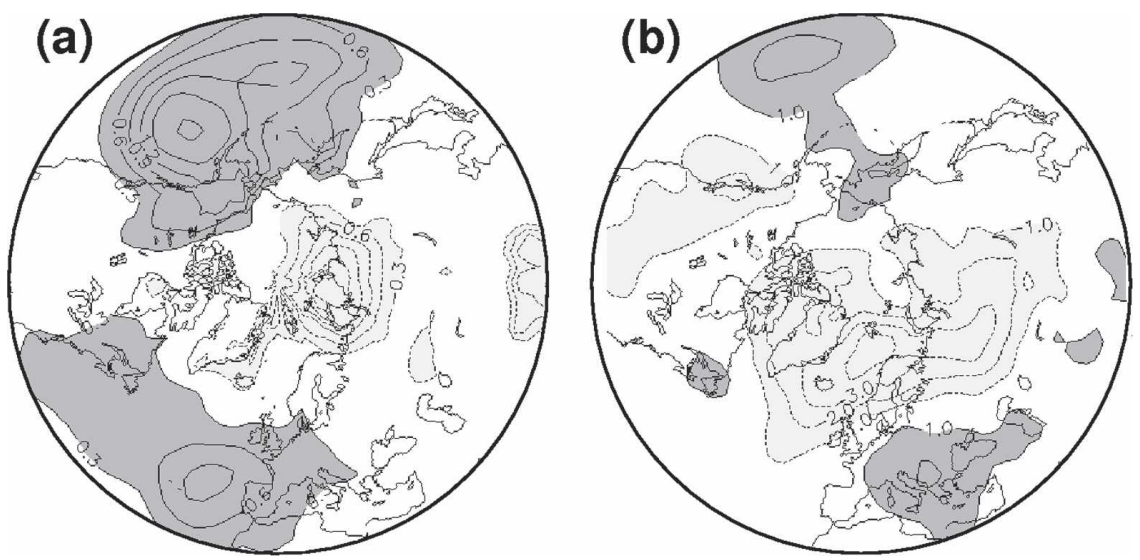

FIG. 5. (a) Mean winter (DJF) differences in sea level pressure between decadal means, 1990-1999 minus 1980-1989, where the values used are the averages of the ensemble members. Dotted lines/light shadings are negative and solid lines/dark shadings are positive differences (0.3-hPa contour interval). (b) NCEP reanalysis anomalies over the same periods at 1 -hPa contour intervals.

compared with relatively high areas in the preceding and following years). The warmest year in the majority of the simulation members and observed SAT is 1995 (Fig. 4a). It is suggested that the instantaneous feedback from sea ice changes into the atmosphere dominates the surface energy balance more strongly in this year because the negative sea ice anomaly was maintained from late winter in this year through to the beginning of the next year, before recovering.

Time series of annual average Arctic precipitation $\left(60^{\circ}-90^{\circ} \mathrm{N}\right)$ for each simulation are shown in Fig. $4 \mathrm{~b}$. The simulated annual mean Arctic precipitation rate is $0.75 \mathrm{~mm} \mathrm{day}^{-1}\left(70^{\circ}-90^{\circ} \mathrm{N}\right)$, which is comparable to observed values. Kattsov and Walsh (2000) suggest that a large portion of the twentieth-century increase in Arctic precipitation is attributable to sea ice boundary and sea surface temperature conditions based on model/ observation comparisons. Observational data over the Arctic are hindered by sparse station networks and undercatch of solid precipitation (Kattsov and Walsh 2000), so consequently the simulated data have been compared to National Centers for Environmental Prediction (NCEP) reanalysis. Modeled results show a magnitude of interannual variation similar to reanalysis. The modeled time series of precipitation was significantly anticorrelated with annual mean sea ice area, whereas the NCEP reanalysis was not (although this could be an artifact of the reanalysis processing). The highest correlation in the model was achieved with summer sea ice area, which is the season with maximum Arctic precipitation.

The NAO (Hurrell 1995) is the leading mode of wintertime variability (climate variability is defined here as fluctuation in climate, which could last for a specified period of time, usually of the order of years to decades) in the Northern Hemisphere, defined as an index of normalized sea level pressure differences between Icelandic low and Azores high. In section 2a evidence of the impact of the NAO on sea ice variability (Partington et al. 2003) was mentioned. Here, a simulated NAO index has been calculated to investigate the potential for sea ice to directly influence North Atlantic variability. The index was based on the normalized difference in December-February (DJF) mean sea level pressure (MSLP) anomalies between $42.5^{\circ} \mathrm{N}, 15^{\circ} \mathrm{W}$ and $67.5^{\circ} \mathrm{N}$, $7.5^{\circ} \mathrm{W}$. Over the period $1980-2000$ the observed NAO index (Hurrell 1995) has had a tendency to be positive (Fig. 4c). Similar to SAT and precipitation time series, comparison of modeled and observed NAO indices reveals a smaller interannual variability in the modeled data. The ensemble mean shows some tendency to be positive in the late 1980s and early 1990s, similar to observations. However, there is no correlation between the time series for prescribed sea ice and simulated NAO.

Serreze et al. (1997) describe large reductions in MSLP over the Arctic Ocean, which locally exceed 4 $\mathrm{mb}$, while increases were observed over central Europe and the Northeastern Pacific between 1979 and 1994. Figure 5a shows a similar pattern in the modeled results (mapped difference of the 1990-99 average minus the 1980-89 average). The regional reductions over the Arctic reach $2 \mathrm{mb}$. The MSLP reduction over the Arctic Ocean extends over Greenland and Iceland in both modeled and observed fields (NCEP reanalysis MSLP anomalies are displayed in Fig. $5 b$ for comparison). De- 


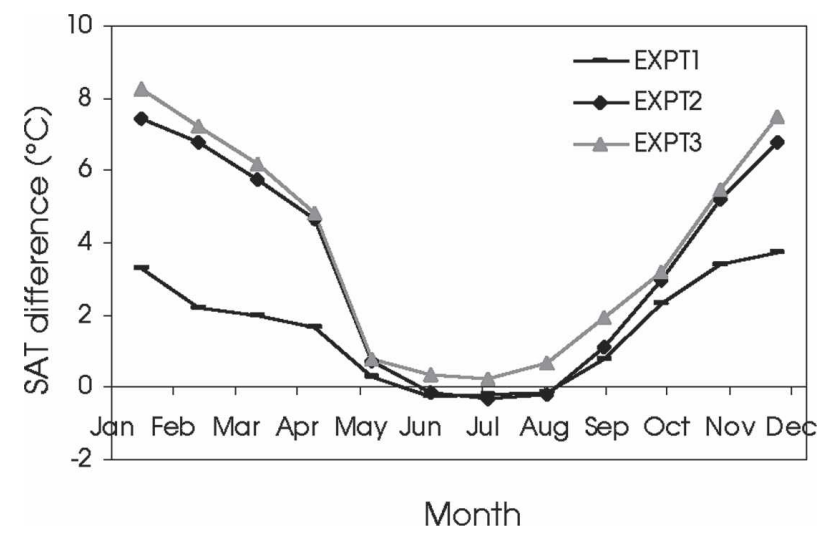

FIG. 6. Difference in decadal average SAT for the Arctic region $\left(60^{\circ}-90^{\circ} \mathrm{N}\right), 2090-99$ minus 2000-09 for each month, in ${ }^{\circ} \mathrm{C}$, for EXPT1, EXPT2, and EXPT3.

creases in sea ice concentrations have directly contributed to changes in atmospheric circulation in a manner strongly resembling observational patterns.

\section{b. Twenty-first-century climate under decreasing Arctic sea ice cover}

\section{1) Temperature}

Global annual mean surface air temperature increases by $0.14^{\circ} \mathrm{C}$ in EXPT1, $0.27^{\circ} \mathrm{C}$ in EXPT2, and $0.30^{\circ} \mathrm{C}$ in EXPT3, during the period 2000-2100. These are driven mostly by temperature increases over the Arctic ( $>60^{\circ}$ latitude) of $1.6^{\circ} \mathrm{C}, 3.4^{\circ}$, and $3.9^{\circ} \mathrm{C}$, respectively, the majority of which occur in the winter months. No increase is recorded in summer SAT in the simulations that use climatological SSTs (Fig. 6: EXPT1 and EXPT2) in spite of the fact that the largest decreases in sea ice were in the summer. In summer, the surface temperature is forced to remain low because of the imposed SSTs. This has been observed with previous atmospheric model studies (e.g., Parkinson et al. 2001). In a fully coupled model, we would expect the summer sea surface temperatures to increase as sea ice area decreases due to greater radiative fluxes, albeit only by a small amount (Kattenberg et al. 1996). In EXPT3, where a representation of such an increase in SSTs has been incorporated, summer mean Arctic SAT increases by $0.3^{\circ} \mathrm{C}$ compared to $7^{\circ} \mathrm{C}$ in winter (Fig. 6), even though the prescribed SST increase is greater in the summer months. In all three experiments, the magnitude of the seasonal cycle of mean Arctic SAT is reduced because of the winter warming, due to decreasing sea ice. The months where maximum/minimum SAT occurs remain unchanged.

Examination of regional differences between decades 2000-09 and 2090-99 show that local winter SAT increases can be up to $16^{\circ} \mathrm{C}$ in EXPT1 (Fig. 7a). In EXPT2 local winter SAT increases of up to $20^{\circ} \mathrm{C}$ occur (Fig. 7b), and up to $22^{\circ} \mathrm{C}$ in EXPT3 (Fig. 7c). Statistically significant changes in SAT occur only at high northern latitudes $\left(>50^{\circ} \mathrm{N}\right)$, mostly over ocean directly over sea ice differences extending onto North America and Greenland, with smaller increases over the north Eurasian coast. The increases are primarily due to large upward sensible heat flux from the ocean directly over the areas within the ice extent where open water has increased. Observed values of sensible and latent heat fluxes over leads can exceed 400 and $130 \mathrm{Wm}^{-2}$, respectively (Andreas et al. 1979). Low-level circulation patterns transport air south out of the Arctic over North America, resulting in the propagation of warmer temperatures. Similar circulation does not occur over Eurasia, and hence temperature changes are smaller.

As mentioned previously, in EXPT1 and EXPT2 there are no significant changes in SAT in summer because of the use of a climatological SST field. EXPT3 does show significant SAT increases in summer [Fig. $7 \mathrm{~d}$; June-August (JJA)]. These are much smaller than in winter (up to $2.5^{\circ} \mathrm{C}$ locally) and are located directly over ocean where the largest losses of sea ice are prescribed. The smaller impact on summer climate occurs because the surface heat fluxes are much smaller as a result of reduced ocean-atmosphere temperature gradients. Increases in summer SSTs due to lower sea ice concentrations are also restricted in reality by the input of sea ice meltwater (at approximately $0^{\circ} \mathrm{C}$ ).

It should be noted that surface heat fluxes are affected by the prescribed ice depths, as well as the ice concentration. Ice depth was calculated as a function of ice concentration, and consequently, the thickness of much of the Arctic ice cover in EXPT2 was lower than in EXPT1. As discussed in Maykut (1978), the heat loss through $0.5 \mathrm{~m}$ of ice can be an order of magnitude higher than through multiyear ice. In EXPT1 and EXPT2 the reduction in winter ice concentrations is not sufficient to decrease ice depth such that there are impacts on heat fluxes through ice in the Central Arctic. The difference in ice depth is larger in summer, but as the summer climate is much less sensitive to sea ice, this has a negligible effect.

The spatial extent of simulated SAT changes in the twenty-first century is much more limited than the current observed trends. The largest observed temperature increases have occurred over mid-/high-latitude land in the Northern Hemisphere $\left(40^{\circ}-70^{\circ} \mathrm{N}\right)$, although both hemispheres have warmed in recent decades (Serreze et al. 2000). Changes in modeled temperature due to sea ice decreases alone do not propagate to lower lati- 

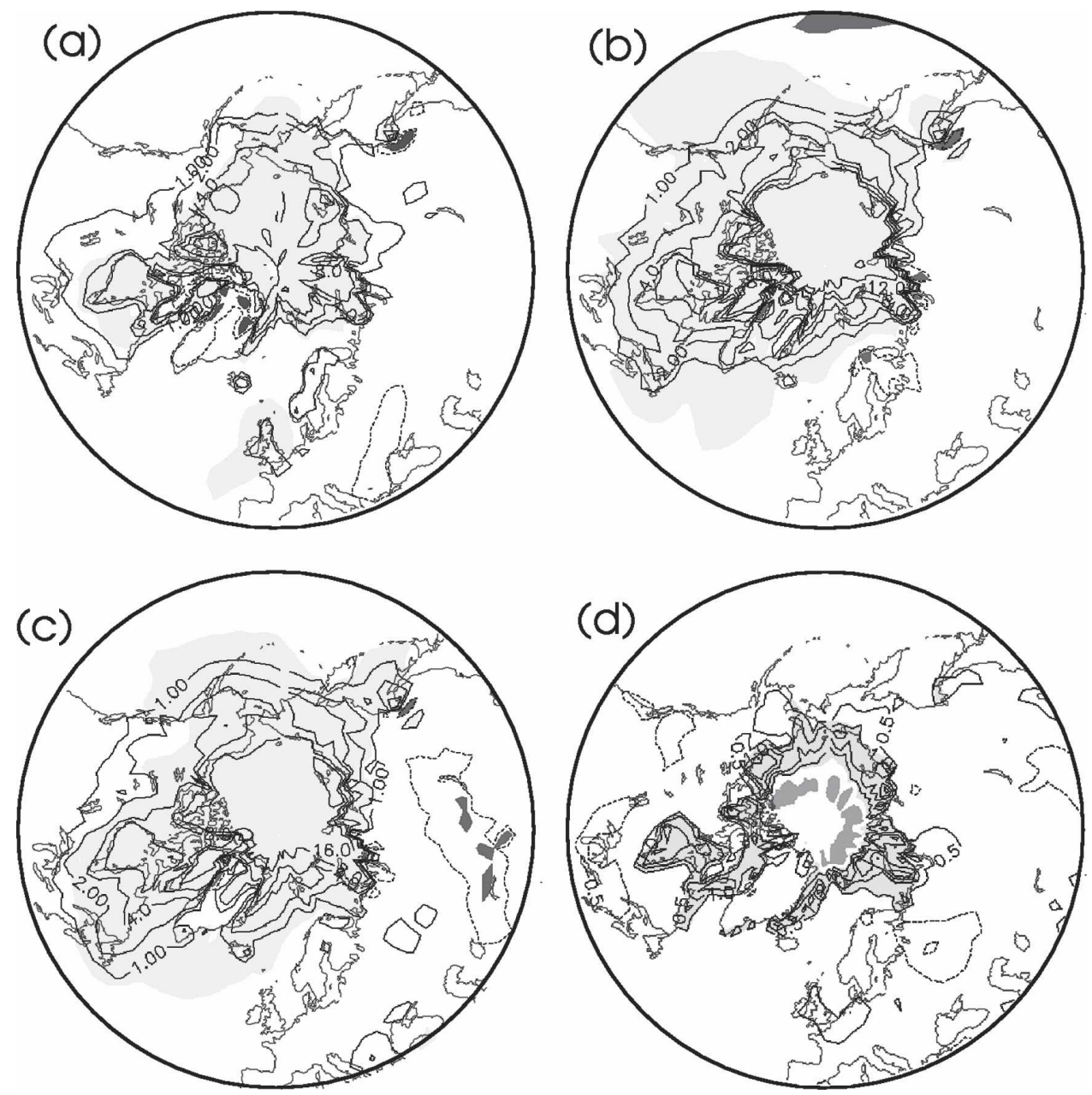

FIG. 7. Mean differences in SAT between decadal means (2090-2099 minus 2000-2009) for (a) EXPT2 DJF, (b) EXPT1 DJF, and EXPT3 (c) DJF and (d) JJA. Shading indicates regions where the Student's $t$-test statistic exceeds the $95 \%$ confidence level.

tudes or vertically in the troposphere above $\sim 700 \mathrm{hPa}$ (Fig. 8; data from EXPT2), as was also found by Magnusdottir et al. (2004) and Alexander et al. (2004). The differences between modeled and observed spatial patterns in SAT suggest that sea ice impacts in the atmosphere affect local temperatures, but that other nonsea-ice influences are important for explaining the observed spatial features at lower latitudes, and/or feedback mechanisms involving ocean circulation are potentially required to enable propagation of temperature anomalies outside higher latitudes.

\section{2) Precipitation and $P-E$}

Coupled model simulations under global warming scenarios predict increases in precipitation related to higher water vapor content and convergence of poleward vapor transport (Kattenberg et al. 1996). In the

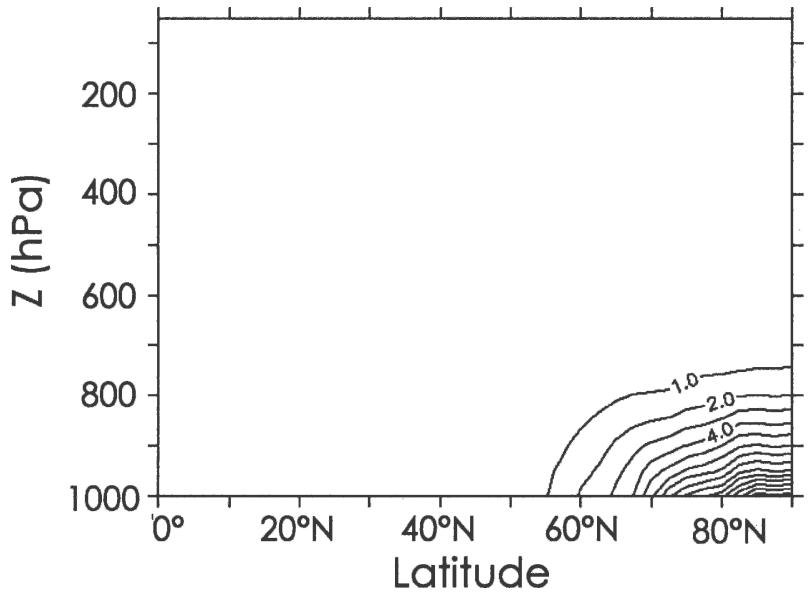

FIG. 8. Zonally averaged temperature change in EXPT2 as a function of geopotential height, $Z$ for the 2090-99 winter (DJF) average minus the $2000-09$ average $\left(1^{\circ} \mathrm{C}\right.$ contour intervals). 
current simulations sea ice variations alone produced an increase in Arctic $\left(60^{\circ}-90^{\circ} \mathrm{C}\right)$ annual precipitation of $0.15 \mathrm{~mm} \mathrm{day}^{-1}(+14 \%)$ in EXPT2, whereas in the more conservative simulation, EXPT1, the increase was only $0.05 \mathrm{~mm} \mathrm{day}^{-1}(+5 \%)$. This increase occurs mainly in winter and spring, with no significant changes in summer, when precipitation is highest over the Arctic, not even in EXPT3.

Maps of winter precipitation differences between the 2000-09 average and 2090-99 average are displayed in Fig. 9a. Directly over regions of decrease in Arctic sea ice extent, an increase in winter evaporation (not shown) is simulated where the sea ice fraction is lower. In the model, this leads to an increase in convective and low cloud cover in these regions in winter (and autumn/ spring) and an increase in precipitation, mainly over the Central Arctic basin. The largest Arctic precipitation increases occur over the marginal ice zone, as found also by Kattsov and Walsh (2000) in atmospheric simulations driven by changing sea ice, SSTs, and $\mathrm{CO}_{2}$. There are also precipitation increases over regions of western Europe and off the east coast of North America (along the North Atlantic storm track), most prevalent in the EXPT2 ensemble mean. Decreases in winter precipitation occur over the initial (1980s) marginal ice area (Bering, Okhotsk, and GIN seas). In these regions, where ice cover is already much reduced in the 2000-09 winter average, the ocean-toatmosphere latent heat flux is reduced (due to increasing atmospheric humidity). As a result, there is reduced precipitation over areas around southern Greenland and the Labrador Sea, as well as Iceland and Svalbard in EXPT2, whilst higher precipitation is seen over northern Greenland and the Canadian Archipelago and central Arctic areas.

The three experiments show similar general spatial anomalies, especially the significant increase in precipitation over the Arctic Ocean. The positive anomalies are larger and more widespread in EXTP2 and EXPT3 than EXPT1, as would be expected given the larger decrease in sea ice. The experiments all display decreased precipitation over the West Coast of the United States, most clearly seen in EXPT3, but also apparent in EXPT2 and EXPT1. Similar reductions in precipitation over western North America were obtained by Sewall and Sloan (2004) using an atmospheric model driven with decreasing sea ice and increasing SSTs, which they related to changes in storm track position.

Changes in precipitation minus evaporation $(P-E)$ may be more relevant to examine than precipitation alone. Variations in $P-E$ over the Arctic Ocean may impact freshwater transports into the North Atlantic
(Serreze et al. 2000) and may be an important control upon changes in ocean circulation (Stocker et al. 1992). Two observational studies of $P-E$ over the Arctic found no significant trends in the last few decades (Walsh et al. 1994; Serreze et al. 1995). Atmospheric simulations by Alexander et al. (2004) forced with observed sea ice anomalies also found that most changes in evaporation were compensated for by changes in precipitation.

Here, the modeled patterns of winter $P-E$ change from the 2000-09 average to the 2090-99 average are shown in Fig. 9b. Large changes in $P-E(>0.2 \mathrm{~mm}$ day $^{-1}$ ) are not as widespread over the Arctic as changes in precipitation. In the central Arctic Basin and East Siberian Sea there is an increase in both precipitation and evaporation but slightly negative change in $P-E$ in all the simulations. This results from a warmer lower atmosphere, which can hold more moisture, so that the increase in evaporation is larger than the increase in precipitation. Negative $P-E$ anomalies in the Central Arctic are largest in EXPT3, as a result of warming SSTs. In areas where the decrease in winter sea ice has been greatest (Bering Straits, GIN, and Barents Seas) and also North Pacific and western North Atlantic (along storm tracks), there are significant positive changes in $P-E$ simulated in EXPT2, which would lead to freshening of waters in these regions. This is more clearly seen in the EXPT2 ensemble mean than the other simulations. The spatial pattern of $P-E$ trends in EXPT2 suggests an increase in $P-E$ over some areas where there is land ice, such as Svalbard and northern parts of Greenland. An increase in precipitation is accompanied by an increase in SAT. However, since temperatures do not exceed the melting point in winter and do not change in summer, it may be likely that changes in the hydrological cycle result in accumulation of land ice and changes in snow cover in some regions.

\section{3) Atmospheric circulation}

In section 3a, the changes in MSLP from 1980 to 2000 were discussed. Spatial patterns of modeled changes resembled those observed during recent decades (Fig. 5), although the magnitude of the changes was half of those observed. During the modeled twenty-first century, there is a continued decrease in the winter MSLP Arctic high with a more extensive spatial pattern reaching into the Canadian Arctic Archipelago and Bering Sea (Fig. 10). There are also smaller increases near the Azores high in EXPT1 and EXPT2, although mostly not statistically significant anomalies. Unlike in Fig. 5, there is an average decrease in MSLP over the Bering 
(a)
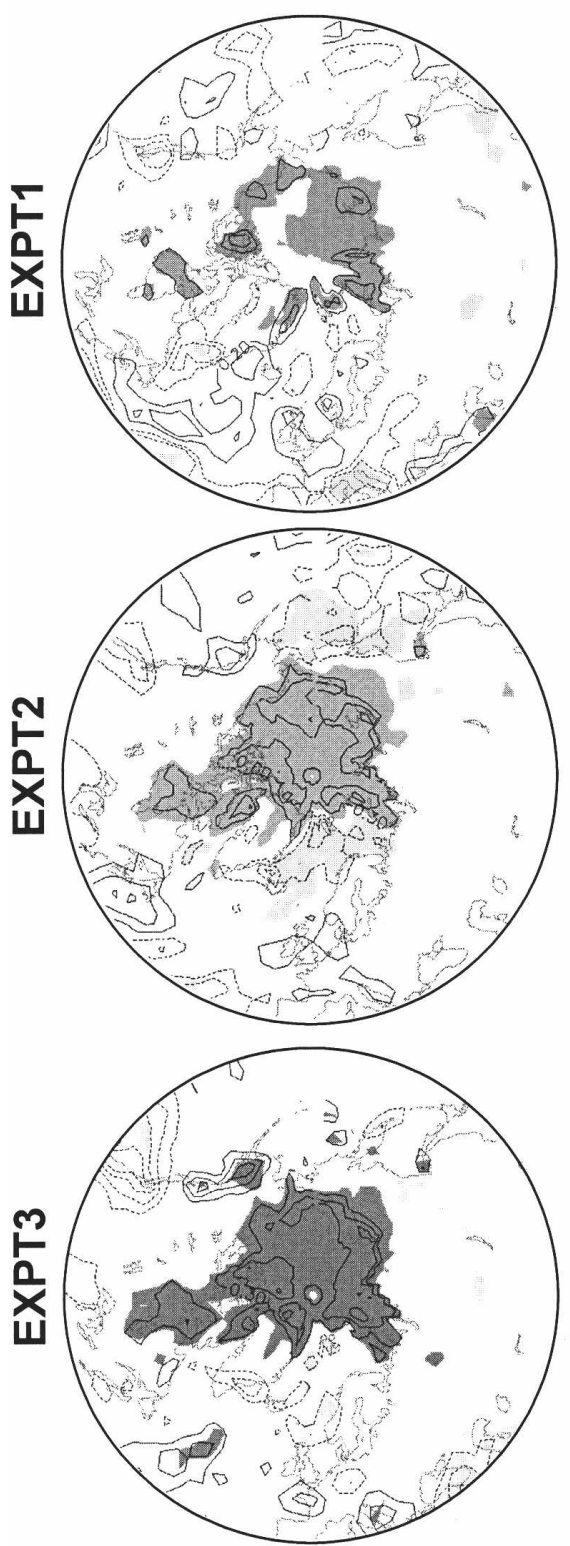

(b)
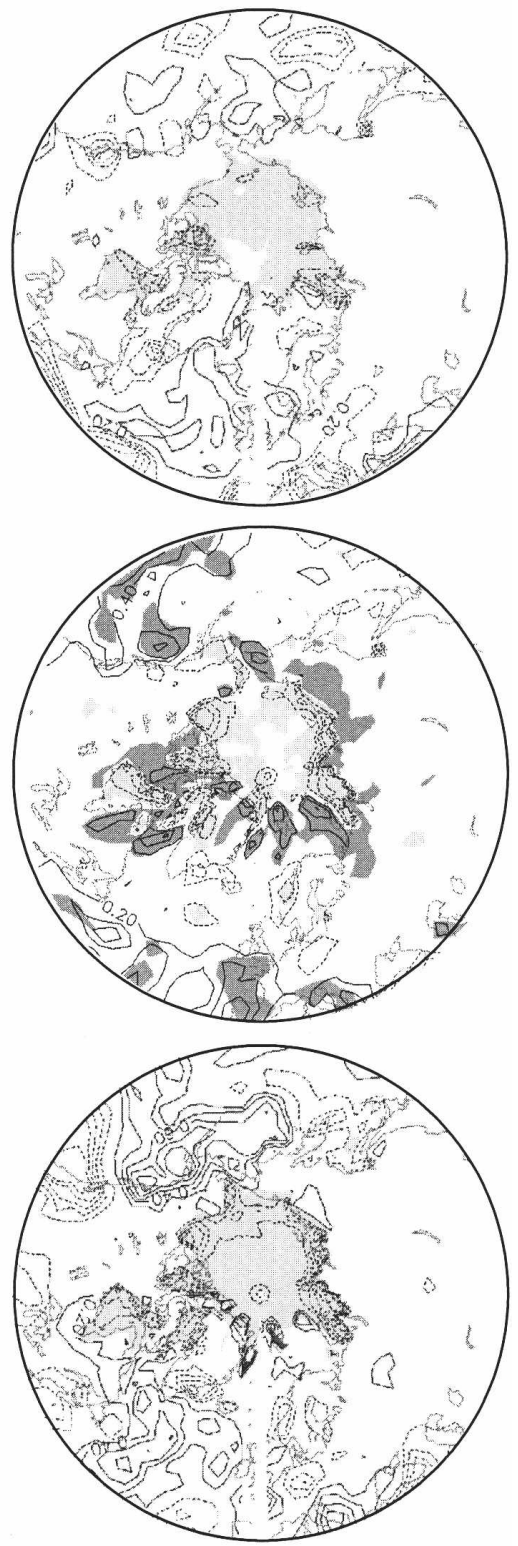

FIG. 9. (a) Total precipitation rate changes 2090-99 DJF average minus 2000-09 DJF average for EXPT1, EXPT2, and EXPT3. Contour interval is $0.1 \mathrm{~mm} \mathrm{day}^{-1}$, except EXPT3, at $0.3 \mathrm{~mm}$ day $^{-1}$. (b) Precipitation minus evaporation $(P-E)$ difference. Contour interval is $0.2 \mathrm{~mm} \mathrm{day}^{-1}$. Shading denotes regions where the $t$ statistic exceeds the $95 \%$ level; dark (light) shading indicates significant positive (negative) changes.

Sea/North Pacific and North Atlantic. Decreases in MSLP over the Arctic locally exceed $4 \mathrm{mb}$ in EXPT1, 5 $\mathrm{mb}$ in EXPT2, and $6 \mathrm{mb}$ in EXPT3. Significant anomalies are less extensive in simulation EXPT1. The widespread MSLP decrease is the result of the trend toward a warmer, less stable atmosphere. A direct atmospheric response to warm SAT anomalies is a drop in MSLP and anomalous cyclonic surface winds.
In accordance with a less stable atmosphere, changes in Northern Hemisphere storm tracks occur. Storm tracks are responsible for a large proportion of midlatitude precipitation, and therefore these changes give rise to much of the change in midlatitude precipitation (Fig. 9a). Storm track activity has been calculated using the high-pass transient poleward temperature flux at $850 \mathrm{hPa}$, showing areas of maximum high-frequency 


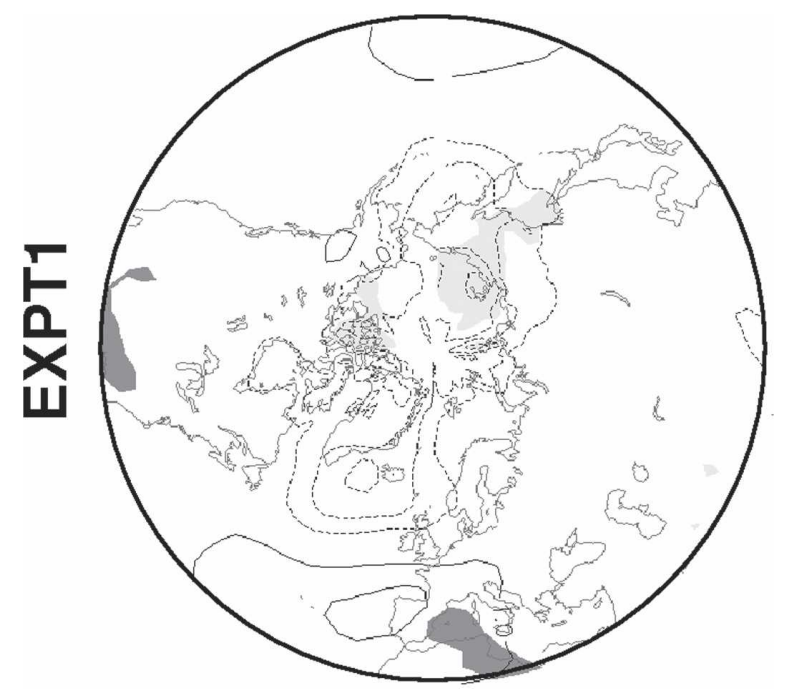

variability (Fig. 11a, shaded). Changes in storm track strength (Figs. 11a or 11b, contours; only EXPT2 results are shown) display a meridional dipole structure. This corresponds to a sharpening of the storm track, with an enhancement at the start of the North Atlantic track off the east coast of North America and to a lesser degree over Europe. The North Pacific storm track shifts slightly south. In addition, there is a widespread weakening of the storm track from the end of the $\mathrm{Pa}$ cific Ocean, and across North America. This weakening of the storm track is consistent with the weakening of the meridional temperature gradient (due to a warmer Arctic, accompanied by negligible temperature change at lower latitudes). However, the increase in the storm track over the west Atlantic is inconsistent with the changes in temperature gradient. In this more southerly region, diabatic processes, specifically latent heating, may also be important. Release of latent heat through condensation may positively feed back on the growth of the storm track. In addition, there is a strengthening of the trough over east North America (and also over the North Pacific), which results in a stronger jet over the eastern seaboard on North America, and hence potentially influencing the North Atlantic storm track. This change in the planetary waves may be associated with the changes in the storm tracks upstream of the North Atlantic (Hoskins and Valdes 1990). The suppression of storm tracks by a strong jet (e.g., Nakamura 1992; Nakamura et al. 2002) may explain some aspects of the weakening of the storm track over the North Pacific but is of less relevance to the North Atlantic, where the overall jet strength is weaker than in the North Pacific.

While there is a change in the mean winter atmospheric circulation in terms of MSLP and storm track activity due to decreases in sea ice, there is no significant trend in wintertime NAO variability, based on the normalized difference in DJF mean sea level pressure anomalies between $42.5^{\circ} \mathrm{N}, 15^{\circ} \mathrm{W}$ and $67.5^{\circ} \mathrm{N}, 7.5^{\circ} \mathrm{W}$. Figure 12 represents the NAO index from 1980 to 2100 from one of the ensemble members of EXPT2. The NAO indices display no trend or periodicity in interannual variation. No trend was observed in EXPT1 or EXPT3. The isolated decline in sea ice enforced in this experiment does not appear to have an impact on this major mode of wintertime climate variability.

$\leftarrow$

FIG. 10. Mean winter (DJF) differences in sea level pressure between decadal means (2090-2099 minus 2000-2009) for each experiment, in mb. Light (dark) shading indicates regions of negative (positive) anomalies where the $t$ statistic exceeds the $95 \%$ confidence level. 

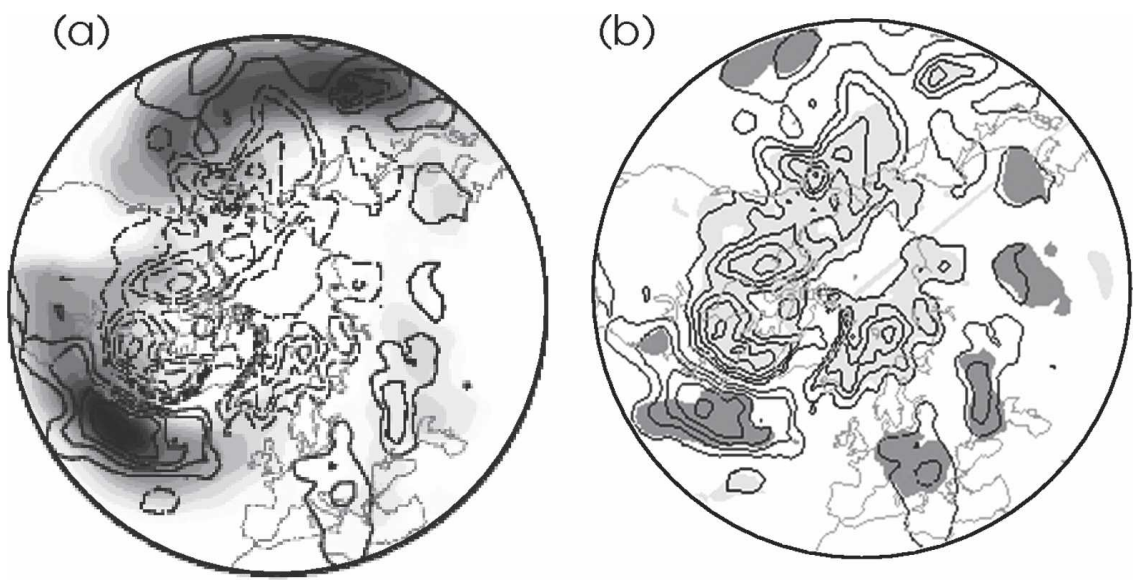

FIG. 11. (a) Simulated storm track activity in the Northern Hemisphere, EXPT2 average, calculated from the high-pass transient poleward temperature flux $\left(\mathrm{m}^{2} \mathrm{~s}^{-2}\right)$ at $850 \mathrm{hPa}$ in DJF averaged over years 2000-09. Shaded contour interval is $1 \mathrm{~m}^{2} \mathrm{~s}^{-2}$. Storm track anomalies (2090-99 average minus 2000-09 average) are plotted over in line contours. (b) Same as in (a), but contour interval is $0.5 \mathrm{~m}^{2} \mathrm{~s}^{-2}$, with dark (light) shading representing areas of significant positive (negative) change.

\section{4) Radiative CHARACTERISTICS}

Because of the prescription of SSTs, the model does not fully conserve energy, since energy absorbed in the ocean is not permitted to warm it. Consequently, the net radiation at the top of the atmosphere (TOA) in these simulations is nonzero. Time series of annual mean TOA net radiation show a negative balance in all simulations (more incoming radiation than outgoing). In EXPT1 and EXPT2 the net radiation balance becomes increasingly negative throughout the simulation, decreasing by 0.12 and $0.30 \mathrm{~W} \mathrm{~m}^{-2}$ from 1980 to 2100 . This results from a combination of an increase in outgoing longwave (LW) radiation, due partly to greater area of relatively warm open-ocean being exposed, but also because larger decrease in upward shortwave (SW) radiation, due to greater absorption of SW at the sur-

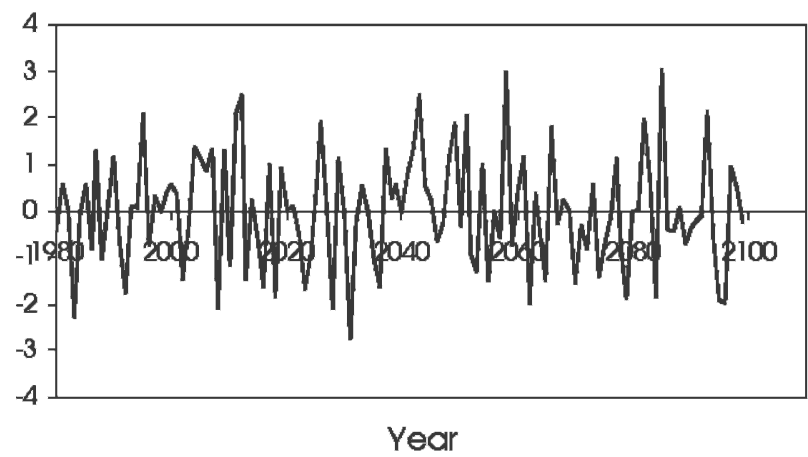

FIG. 12. Time series of NAO index from ensemble member $\mathrm{m} 1$ in EXPT2 from 1980 to 2099. face given a lower overall surface albedo. The overall change is small compared to the expected changes in radiative forcing during this century. In EXPT3, the incorporation of increasing SSTs also results in a negative TOA net radiation, but no significant trend (net radiation decreases by only $-0.03 \mathrm{~W} \mathrm{~m}^{-2}$ ), for the reason that the decrease in upward SW radiation is matched by the increase in outgoing LW radiation.

\section{Discussion}

The impact on climate of the twenty-first-century decline in the Arctic sea ice cover has been investigated. Observations of sea ice in recent decades show an approximately linear decrease in extent, while there have been coherent changes in other environmental fields, such as Arctic temperatures and precipitation. The purpose of this study was to examine the spatial and temporal patterns of change in the climate that might result given a continuing decrease in sea ice, using prescribed sea ice fields from years 1980 to 2100 to force HadAM3. The sea ice fields were based on satellite passive microwave radiometer data derived with the Bootstrap algorithm and contained the observed data from 1980 to 2000. Two scenarios of ice decline were used to investigate the climate sensitivity to sea ice; one predicted a moderate decrease (EXPT1) and the other predicted a more severe reduction (used in EXPT2 and EXPT3).

During simulations driven with observed sea ice, from 1980 to 2000, annual Arctic average SAT increases at a rate of $0.16^{\circ} \pm 0.06^{\circ} \mathrm{C}$ per decade, which is 
half the observed rate over the same period. Increases in annual Arctic average SAT from $2000-99$ were $1.6^{\circ} \mathrm{C}$ in EXPT1, $3.4^{\circ} \mathrm{C}$ in EXPT2, and $3.9^{\circ} \mathrm{C}$ in EXPT3. With a moderate rate of sea ice decline (EXPT1), the simulated SAT increases at roughly the same rate in 2000-99 as 1980-2000. If a severe twenty-first-century sea ice decline is prescribed (EXPT2 and EXPT3) then the rate of SAT increase is around twice that value. The comparisons are subject to errors due to internally generated interannual variations in the simulations (which are reduced by performing ensemble runs for EXPT2) and interannual variation in the observed sea ice record.

Modeled trends suggest that although decreases in ice extent were prescribed in each month, these only have a significant impact on wintertime SATs, as long as SSTs are not allowed to increase. Winter warming in simulated years 1980-2000 occurs mainly over Fram Strait and the GIN and Barents Seas. By the end of the twenty-first century, significant increases occur in all simulations over the entire Arctic basin, regardless of whether there is much open water prescribed in this region (as in EXPT2) or not (EXPT1). Winter reduction of total Arctic sea ice area of $21 \%$ (from 2000 to 2099) produced local maximum increases of $20^{\circ} \mathrm{C}$ in the case of a larger sea ice decline (EXPT2). Even in the conservative scenario (EXPT1), winter decreases in ice area of $7 \%$ result in local increases of up to $16^{\circ} \mathrm{C}$.

It is well known that satellite PMR data suffer from inaccuracies regarding interpretation of areas of summer surface melt ponds. Areas with surface melt may be incorrectly interpreted as open water. Because of recent increases in surface temperature, it is probable that the amount of surface melting has increased also. The calculated monthly trends used to form the predicted ice decreases used here may be slightly overestimated as a result. Fortuitously, the summer climate is much less sensitive to sea ice than in winter. There are no significant changes to summer SATs in EXPT1 or EXPT2, both of which used a climatological SST field. When an increasing SST field was prescribed in EXPT3 there were small increases in temperature of $0.3^{\circ} \mathrm{C}$ in the Arctic average and up to $2.5^{\circ} \mathrm{C}$ locally, but far less than winter increases of up to $22^{\circ} \mathrm{C}$.

Changes in SAT are largest over ocean and are limited to northern high latitudes, unlike current observations of climate warming, where increases have been largest over land. Reductions in sea ice do induce more widespread changes in atmospheric circulation. As a result of increased temperatures, a reduction in MSLP occurs that extends to the North Pacific and North Atlantic. This appears to have a significant effect for mid- latitude storm tracks, which increase in intensity throughout the simulations. All these changes have an important role in altering precipitation patterns, especially over western and southern Europe in winter, which in EXPT2 experience significant increases. With regards to global warming, impacts for the hydrological cycle are potentially more important than increasing temperatures. There may be implications for terrestrial ice mass balance, which ultimately influences the salinity of Arctic waters also. Increases in modeled precipitation occurred over areas of ocean where sea ice area decreased. In addition, increases in $P-E$ were observed over some parts of the Arctic covered by land ice (EXPT2). A short-term net accumulation over these glaciers and ice caps may occur if there is a further decrease in sea ice in those regions. Other regions may experience decreases in precipitation, such as Iceland, and also parts of the west coast of North America that already suffer from limited water resources (Sewall and Sloan 2004).

In EXPT2, a greater loss of sea ice area was prescribed than in EXPT1, as well as small reductions in ice concentrations in the Central Arctic not included in EXPT1. The magnitude of the climate changes induced depends on the scenario of sea ice decline used. However, the spatial extents of SAT anomalies produced are similar in EXPT1 and EXPT2. The spatial extent of MSLP changes is also similar. The prescription of open water within the ice pack does influence more strongly the extent of changes in precipitation over the Arctic.

A caveat to this study is that, while in one simulation increasing SSTs were prescribed, no coupled ocean model was used. This allowed us to isolate the effects of sea-ice-induced changes in the albedo and surface heat flux but consequently underestimates the overall effect of sea ice on climate change. The incorporation of increasing SSTs corresponding to sea ice decreases results in year-round higher temperatures, but by $<1^{\circ} \mathrm{C}$ compared to climatological SST. Feedbacks between the hydrological cycle and the ocean and effects such as brine rejection were not included in this study. Changes in the Arctic freshwater budget may have effects in the Atlantic, and possibly the global ocean, through deep convection. This will be the subject of additional simulations. The results of the present study suggest that sea-ice-induced albedo and heat flux changes have a small effect on Northern Hemisphere landmasses, but a more substantial impact on the hydrological cycle.

Acknowledgments. This study was funded under NERC Grant NER/T/S/2001/01279 under the NERC COAPEC theme. Computer time was provided by the NERC Centres for Atmospheric Sciences (NCAS). 


\section{REFERENCES}

Alexander, M. A., U. M. Bhatt, J. E. Walsh, M. S. Timlin, J. S. Miller, and J. D. Scott, 2004: The atmospheric response to realistic Arctic sea ice anomalies in an AGCM during winter. J. Climate, 17, 890-905.

Andreas, E. L, C. A. Paulson, R. M. Williams, R. W. Lindsay, and J. A. Businger, 1979: Turbulent heat-flux from Arctic leads. Bound.-Layer Meteor., 17, 57-91.

Bamber, J. L., W. Krabill, V. Raper, and J. Dowdeswell, 2004: Anomalous recent growth of part of a large Arctic ice cap: Austfonna, Svalvard. Geophys. Res. Lett., 31, L12402, doi:10.1029/2004GL019667.

Cavalieri, D. J., J. P. Crawford, M. R. Drinkwater, D. T. Eppler, L. D. Farmer, R. R. Jentz, and C. C. Wackerman, 1991: Aircraft active and passive microwave validations of sea-ice concentrations from the DMSP SSM/I. J. Geophys. Res., 96, 21 989-22008.

Comiso, J. C., 2002a: Correlation and trend studies of the sea-ice cover and surface temperatures in the Arctic. Ann. Glaciol., 34, 420-428.

_ 2002b: A rapidly declining perennial sea ice cover in the Arctic. Geophys. Res. Lett., 29, 1956, doi:10.1029/ 2002GL015650.

— SMMR and DMSP SSM/I. National Snow and Ice Data Center, Boulder, CO. [Available online at http://nsidc.org/data/ nsidc-0079.html.]

_ 2003: Warming trends in the Arctic from clear sky satellite observations. J. Climate, 16, 3498-3510.

— D. Cavalieri, C. Parkinson, and P. Gloersen, 1997: Passive microwave algorithms for sea ice concentration: A comparison of two techniques. Remote Sens. Environ., 60, 357-384.

Cox, P. M., R. A. Betts, C. B. Bunton, R. L. H. Essery, P. R. Rowntree, and J. Smith, 1999: The impact of new land surface physics on the GCM simulation of climate and climate sensitivity. Climate Dyn., 15, 183-203.

Deser, C., J. E. Walsh, and M. S. Timlin, 2000: Arctic sea-ice variability in the context of recent atmospheric circulation trends. J. Climate, 13, 617-633.

—, G. Magnusdottir, R. Saravanan, and A. Phillips, 2004: The effects of North Atlantic SST and sea ice anomalies on the winter circulation in CCM3. Part II: Direct and indirect components of the response. J. Climate, 17, 877-889.

Dowdeswell, J. A., and Coauthors, 1997: The mass balance of circum-Arctic glaciers and recent climate change. Quat. Res., 48, 1-14.

Gregory, J. M., P. A. Stott, D. J. Cresswell, N. A. Rayner, C. Gordon, and D. M. H. Sexton, 2002: Recent and future changes in Arctic sea ice simulated by the HadCM3 AOGCM. Geophys. Res. Lett., 29, 2175, doi:10.1029/2001GL014575.

Hoskins, B. J., and P. J. Valdes, 1990: On the existence of storm tracks. J. Atmos. Sci., 47, 1854-1864.

Hurrell, J. W., 1995: Decadal trends in the North Atlantic Oscillation regional temperatures and precipitation. Science, 269, 676-679.

Johannessen, O. M., and Coauthors, 2004: Arctic climate change: Observed and modelled temperature and sea-ice variability. Tellus, 56A, 328-341.

Johns, T. C., R. E. Carnell, J. F. Crossley, J. M. Gregory, J. F. B. Mitchell, C. A. Senior, S. F. B. Tett, and R. A. Wood, 1997:
The second Hadley Centre coupled ocean-atmosphere GCM: Model description, spinup and validation. Climate Dyn., 13, 103-134.

Kattenberg, A., and Coauthors, 1996. Climate modelsProjections of future climate. Climate Change 1995: The Science of Climate Change, J. T. Houghton et al., Eds., Cambridge University Press, 289-357.

Kattsov, M. K., and J. E. Walsh, 2000: Twentieth-century trends of Arctic precipitation from observational data and a climate model simulation. J. Climate, 13, 1362-1370.

Laxon, S., N. Peacock, and D. Smith, 2003: High interannual variability of sea ice thickness in the Arctic region. Nature, $\mathbf{4 2 5}$ 947-949.

Lugina, K. M., P. Ya. Groisman, K. Ya. Vinnikov, V. V. Koknaeva, and N. A. Speranskaya, 2003: Monthly surface air temperature time series area-averaged over the 30-degree latitudinal belts of the globe, 1881-2002. Trends Online: A Compendium of Data on Global Change, Carbon Dioxide Information Analysis Center, Oak Ridge National Laboratory, U.S. Department of Energy, Oak Ridge, TN. [Available online at http://cdiac.esd.ornl.gov/trends/temp/lugina/lugina. html.]

Magnusdottir, G., C. Deser, and R. Saravanan, 2004: The effects of North Atlantic SST and sea ice anomalies on the winter circulation in CCM3. Part I: Main features and storm track characteristics of the response. J. Climate, 17, 857-876.

Maslanik, L. A., A. H. Lynch, M. C. Serreze, and W. Wu, 2000: A case study of regional climate anomalies in the Arctic: Performance requirements for a coupled model. J. Climate, $\mathbf{1 3}$, 383-401.

Maykut, G. A., 1978: Energy exchange over young sea ice in the Central Arctic. J. Geophys. Res., 83, 3646-3658.

Nakamura, H., 1992: Midwinter suppression of baroclinic wave activity in the Pacific. J. Atmos. Sci., 49, 1629-1641.

T. Izumi, and T. Sampe, 2002: Interannual and decadal modulations recently observed in the Pacific storm track activity and east Asian winter monsoon. J. Climate, 15, 18551874.

Parker, D. E., C. K. Folland, and M. Jackson, 1995: Marine surface temperature: Observed variations and data requirements. Climate Change, 31 (2-4), 559-600.

Parkinson, C. L., D. J. Cavalieri, P. Gloersen, H. J. Zwally, and J. C. Comiso, 1999: Sea ice extents, areas, and trends, 19781996. J. Geophys. Res., 104 (C9), 20 837-20 856.

—, D. Rind, R. J. Healy, and D. G. Martinson, 2001: The impact of sea ice concentration accuracies on climate model simulations with a GISS GCM. J. Climate, 14, 2606-2623.

Partington, K., T. Flynn, D. Lamb, C. Bertoia, and K. Dedrick, 2003: The late twentieth century Northern Hemisphere sea ice record from U.S. National Ice Center ice charts. J. Geophys. Res., 108, 3343, doi:10.1029/2002JC001623.

Pope, V. D., M. L. Gallani, P. R. Rowntree, and R. A. Stratton, 2000: The impact of new physical parameterisations in the Hadley Centre climate model: HadAM3. Climate Dyn., 16, 123-146.

Räisänen, J., 2001: $\mathrm{CO}_{2}$-induced climate change in CMIP2 experiments: Quantification of agreement and role of internal variability. J. Climate, 14, 2088-2104.

Rind, D., R. Healy, C. Parkinson, and D. Martinson, 1995: The role of sea ice in $2 \times \mathrm{CO}_{2}$ climate model sensitivity. Part I: The total influence of sea ice thickness and extent. J. Climate, 8, 449-463. 
Rothrock, D. A., Y. Yu, and G. A. Maykut, 1999: Thinning of the Arctic sea-ice cover. Geophys. Res. Lett., 26, 3469-3472.

Serreze, M. C., R. G. Barry, and J. E. Walsh, 1995: Atmospheric water vapor characteristics at $70^{\circ} \mathrm{N}$. J. Climate, 8, 719-731.

_ , F. Carse, R. G. Barry, and J. C. Rogers, 1997: Icelandic low cyclone activity: Climatological features, linkages with the NAO, and relationships with recent changes in the Northern Hemisphere circulation. J. Climate, 10, 453-464.

— - and Coauthors, 2000: Observational evidence of recent change in the northern high-latitude environment. Climate Change, 46, 159-207.

Sewall J. O., and L. C. Sloan, 2004: Disappearing Arctic sea ice reduces available water in the American west. Geophys. Res. Lett., 31, L06209, doi:10.1029/2003GL019133.

Singarayer, J. S., and J. L. Bamber, 2003: EOF analysis of three records of sea-ice concentration spanning the last 30 years. Geophys. Res. Lett., 30, 1251-1254.

, P. J. Valdes, and J. L. Bamber, 2005: The atmospheric im- pact of uncertainties in recent Arctic sea ice reconstructions. J. Climate, 18, 3996-4012.

Slonosky, V. C., L. A. Mysak, and J. Derome, 1997: Linking Arctic sea ice and atmospheric circulation anomalies on interannual and decadal timescales. Atmos.-Ocean, 35, 333-366.

Smith, R. N. B., 1990: A scheme for predicting layer clouds and their water-content in a general circulation model. Quart. J. Roy. Meteor. Soc., 116, 435-460.

Stocker, T. F., D. G. Wright, and L. A. Mysak, 1992: A zonally averaged, coupled ocean-atmosphere model for paleoclimate studies. J. Climate, 5, 773-797.

Vinnikov, K. Y., and Coauthors, 1999: Global warming and Northern Hemisphere sea ice extent. Science, 286, 1934-1937.

Walsh, J. E., and M. S. Timlin, 2003: Northern hemisphere sea ice simulations by global climate models. Polar Res., 22, 75-82.

—, X. Zhou, D. Portis, and M. C. Serreze, 1994: Atmospheric contribution to hydrologic variations in the Arctic. Atmos.Ocean, 34, 733-755. 